\title{
UM PASSEIO PELA ESTRUTURA LABIRÍNTICA DE LE CITTÀ INVISIBILI DE ITALO CALVINO ${ }^{1}$
}

\author{
A WALK THROUGH THE MAZELIKE STRUCTURE OF LE CITTA LE CITTÀ \\ INVISIBILI OF ITALO CALVINO
}

\author{
Adriana Lins Precioso ${ }^{2}$
}

\begin{abstract}
Resumo: Este artigo procura revelar como a figura do labirinto, em suas possíveis funções, estrutural e temática, são engendradas na estrutura da obra Le città invisibili (As cidades invisíveis) (1972) do escritor italiano Italo Calvino. Em um processo combinatório de simetria numérica, observa-se a similaridade estrutural do texto com a obra clássica Decameron (1353) de Giovanni Boccaccio e, além disso, investiga-se as predileções do escritor pelo jogo combinatório, pelas formas geométricas, pela revisitação à tradição e pela presença do mito enquanto elemento essencial.
\end{abstract}

Palavras-chave: Le città invisibili. Decameron. Mito do labirinto. Jogo combinatório.

\begin{abstract}
This article aims to reveal how the labyrinth figure, in its possible functions, structural and thematic, are engendered in the structure of the Italian writer Italo Calvino's Le città invisibili (The Invisible Cities) (1972). In a combinatorial process of numerical symmetry, we observe the structural similarity of the text with the classic work Decameron (1353) by Giovanni Boccaccio and, furthermore, we investigate the writer's predilections for the combinatorial game, for geometric forms, for revisiting the tradition and the presence of myth as an essential.
\end{abstract}

Keywords: Le città invisibili. Decameron Maze myth. Combinatory game.

Ítalo Calvino é um dos autores italianos mais estudados na atualidade. Crítico sagaz e escritor de várias obras literárias, possui uma produção intelectual rica, extensa e valorizada, não só no seu país, como também mundialmente. Pasquale Tuscano o considera “Cittadino del

\footnotetext{
${ }^{1}$ Este artigo constitui-se como parte de uma pesquisa mais ampliada na Dissertação de Mestrado intitulada "Invisibilidade e invenção: a poética das cidades em Italo Calvino e Ferreira Gullar" de 2003. As demais informações encontram-se nas referências.

${ }^{2}$ Adriana Lins Precioso tem Pós-Doutorado pelo Programa de Pós-Graduação em Literatura da Universidade de Brasília - PósLit, na área de "Literatura e práticas sociais". Atua como professora do Curso de Letras e do PPGLETRAS - Programa de Mestrado em Letras da UNEMAT- Universidade do Estado de Mato Grosso, Campus de Sinop. É Líder do Grupo de Pesquisa: Estudos Comparativos de Literatura: tendências identitárias, diálogos regionais e vias discursivas - Certificado pelo CNPq.
} 
mondo", devido a sua contemporaneidade e universalidade ao tratar sem suas obras as questões complexas do homem do nosso tempo com refinada crítica e profunda conscientização. Sobre a universalidade da literatura, Calvino afirmou: "Minhas reflexões sempre me levaram a considerar a literatura como universal, sem distinções de língua e caráter nacional, e a considerar o passado em função do futuro.” (CALVINO, 1990-B, p. 9)

Ao “considerar o passado", Calvino envereda pelos caminhos da tradição buscando, nas raízes da narrativa, os fios que entrelacem suas obras. O mito, a lenda e o conto popular são por ele utilizados em inúmeras narrativas. Esses elementos somam-se à crítica de uma sociedade moderna, às complexidades das relações e dos valores humanos e à ideia da literatura artesanal. Todos esses fios formam a tessitura do texto literário nesse escritor, garantindo-lhe um lugar de destaque na literatura contemporânea.

Il sentiero dei nidi di ragno (1947) foi sua primeira publicação. Os críticos anunciam já nesta publicação um estilo que será aprofundado ao longo de sua trajetória como escritor e que mistura um realismo antipsicológico diante de um presente cruel e inocente derivada de uma tensão ideológica de comunista militante. Fantasia e realidade se chocam em narrativas que possuem uma fábula visual e um otimismo vital, tal como apontam Iozzi (2001, p. 46). A tensão dessas duas correntes contratantes revela:

Por um lado, Calvino sente-se atraído por uma imaginação aventureira e fantasiosa, manifestada na sua obra primeiro pela fábula e, depois, pela alegoria. Por outro lado, sente a necessidade de controlar e disciplinar essa mesma imaginação por meio de um engajamento ético-político representado pela sua atividade de ensaísta e pelas obras narrativas definidas como "realistas" ou, mais especificamente, "objetivas". De um lado a livre fantasia criadora; de outro, a vontade de submetê-la à razão. Dessa forma, o escritor é levado a pesquisar os mecanismos estruturais da narrativa pela perspectiva sistemática que busca os paradigmas lógicos de uma arte combinatória imanente ao ato de narrar. (IOZZI, 2001, p. 46)

Esta capacidade de articular os fios constituintes da fábula com um momento histórico reconhecível tornou-se uma marca na trajetória literária de Calvino; várias são as obras resultantes dessa articulação. Os ensaios críticos também fazem parte desse itinerário. Sua produção intelectual é referência junto às suas obras. Assim, é possível estabelecer pontes no desenrolar de suas atividades.

Comunista militante, Italo Calvino inicia sua produção literária com textos engajados que procuravam "exprimir da vida uma crueldade inocente por meio de um realismo anti- 
psicológico, resultante da tensão ideológica (...) transformada em otimismo vital e em fábula visual." (IOZZI, 1998, p. 18). Posteriormente, sua produção desenvolve-se amenizando esse engajamento e dando espaço para a alegorização do realismo social tendo a fábula como ponte para esse processo.

É interessante para nós ressaltar a participação de Calvino no grupo OULIPO (Ouvroir de Littérature Potencielle), fundado por François Le Lionnais em 1960 e que tinha como objetivo a renovação na literatura por meio de jogos combinatórios que valorizavam a matemática e a ciência conjugados na metalinguagem literária. A participação de Calvino inicia-se com sua mudança para Paris em 1964, a partir de então, a literatura passa a ser, para Calvino, "processo combinatório", enriquecido pelos fios de fábula e da história, que compõem as regras do desenvolvimento criativo das narrativas desse escritor e, é neste momento de produção, um dos mais fecundos e criativos da trajetória de Calvino.

Le città invisibili conjuga de forma exemplar esse "processo combinatório" produzido pelo jogo matemático, somado à predileção de Calvino pelas formas geométricas e à sua paixão pelos clássicos da tradição; seu livro é uma reescritura do Il Milione (Il libro delle Meraviglie - 1298), um clássico medieval no qual Marco Polo narra suas viagens pela China, onde permaneceu cerca de vinte anos, servindo de embaixador junto ao imperador mongol Kublai Khan. Dotada de uma estrutura singular, essa obra responde rigorosamente à concepção de Calvino sobre o texto literário, a importância dos clássicos e a conjugação entre jogos matemáticos e formas geométricas para a inovação do fazer literário.

Em seu ensaio sobre "Exatidão" no livro Seis propostas para o próximo milênio (1990B, p. 92), Calvino revela um pouco das suas predileções,

Queria lhes falar de minha predileção pelas formas geométricas, pelas simetrias, pelas séries, pela análise combinatória, pelas proporções numéricas, explicar meus escritos em função de minha fidelidade a uma ideia de limite, de medida... Mas quem sabe não será precisamente essa ideia de limite que suscita a ideia das coisas que não têm fim, como a sucessão de números inteiros ou as retas euclidianas?

O gosto pela combinação é traduzido por Calvino no Le città por meio de uma "exatidão" de números e séries bem definidos e que geram uma multiplicidade na rede de conexões e combinações possíveis. A escolha de onze séries temáticas, desdobradas em cinco cidades cada e distribuídas, nos capítulos intermediários, numa ordenação fixa decrescente que 
obedece rigorosamente à ordem 5,4,3,2,1 somadas a dez cidades no primeiro e nono capítulo, com as respectivas funções de inaugurar e finalizar tais séries, mostram uma "composição geometrizante" que define bem o gosto de Calvino.

A associação de números com temas ou ordenação e desenvolvimento temáticos é reconhecida num outro clássico, o Decameron, obra escrita por Boccaccio, provavelmente em 1353. O título da obra significa "dez dias" ou “dez jornadas". O Decameron apresenta um fio conectivo entre as narrativas, há nessa obra uma espécie de "moldura" (cornice) que entra em consonância com os variados temas desenvolvidos nas narrativas.

A narrativa conta a fuga de dez jovens no período em que a peste negra assolou a cidade de Florença na Itália. São sete moças e três rapazes que se encontram e fogem; sua primeira parada é em uma vila e depois num belo palácio. O enredo obedece, também, a uma formulação matematizada que define a obra, pois dez são os dias em que as narrativas são desenvolvidas e dez são os narradores. Além disso, para cada dia um "rei" ou "rainha" eleitos constituem o painel de narração:

Os dez jovens não são unicamente narradores, mas eles assumem também uma atitude avaliativa nos debates da matéria narrada, daquela realidade isto é realisticamente descrita nas novelas, isto é que contribui para trazer luz organizada e transparente, a ideologia da obra $^{3}$. (JENSEN, 1987, p. 60) (tradução nossa)

A matematização não se detém apenas neste aspecto, a escolha dos números no Decameron carrega um simbolismo muito presente na Idade Média e sua ordenação determina também parte do enredo. Pazzaglia (1993, p. 389) destaca que a escolha de serem 10 narradores divididos em 7 mulheres e 3 homens, faz alusão ao número perfeito, o três da Trindade, número que também está ligado às virtudes teológicas e cardinais. Esse tipo de simbolismo era muito comum na cultura da Idade Média.

\footnotetext{
${ }^{3}$ I dieci giovani non sono unicamente dei narratori, ma essi assumono altresì un atteggiamento valutativo nei confronti della materia narrata, di quella realtá cioè realisticamente descritta nelle novelle, cioè che contribuisce a far venire in luce, ordinata e trasparente, l'ideologia dell'opera. (JENSEN, 1987, p. 60)
} 
Os temas das narrativas obedecem a uma sucessão rigorosamente distribuída nos dias, o que dá forma harmoniosa nos textos. Há dois dias de tema livre, os demais agrupam-se entre êxitos e fracassos: no amor, na aventura e na aquisição de algo muito desejado.

Pode-se traçar paralelos de comparação entre a forma de organizar e distribuir os temas do Le città e do Decameron, já que ambos se valem de uma estrutura rigorosamente ordenada, apoiada em números e definida pelas temáticas. No Le città, as onze séries temáticas são disseminadas ao longo do texto, apresentando a seguinte ordem: 1- "as cidades e a memória", 2- "as cidades e o desejo", 3- "as cidades e os símbolos", 4- "as cidades delgadas", 5- "as cidades e as trocas", 6- "as cidades e os olhos", 7- "as cidades e o nome", 8- "as cidades e os mortos", 9- "as cidades e o céu", 10- "as cidades contínuas e 11- "as cidades ocultas". Cada série desdobra-se em cinco cidades, sendo que as cidades que inauguram as séries finalizam os capítulos, do segundo ao oitavo (penúltimo) capítulo da obra.

A estrutura do Le città constitui-se de nove capítulos, os quais são iniciados e finalizados por textos que apresentam Marco Polo e Kublai Khan dialogando, somando ao todo dezoito textos. Esses textos diferenciam-se das narrações das cidades, em uma primeira instância, graficamente, pois são escritos em itálico; posteriormente, porque colocam em cena o narrador das cidades (Marco Polo) com o seu interlocutor (Kublai Khan), em um processo que evidencia uma gradação na comunicação entre os atores e depois, uma contatada abstração, também gradual, nos diálogos realizados. É preciso ressaltar que o "diálogo não é o limiar da ação mas a própria ação.” (BAKHTIN, 1997, p. 256). Portanto, Marco Polo e Kublai Khan se fazem conhecer pelos conteúdos tratados nos diálogos: as descrições de Marco, os pensamentos de Kublai, os questionamentos, as dúvidas e os confrontos entre ambos adquirem uma certa profundidade filosófica, na medida em que eles chegam a questionar a própria existência, como examina-se no trecho abaixo:

Polo: Pode ser que os terraços deste jardim só estejam suspensos sobre o lago das nossas mentes...

Kublai: ... E por mais longe que as nossas atribuladas funções de comandante e de mercador nos levem, ambos tutelamos dentro de nós esta sombra silenciosa, esta conversação pausada, esta tarde sempre idêntica.

Polo: A menos que não se dê a hipótese oposta: que aqueles que se afanam nos acampamentos e nos portos só existem porque nós dois pensamos neles, fechados neste tapume de bambus, sempre imóveis.

Kublai: Que não existem o esforço, os gritos, as pragas, o fedor, mas apenas esta azaleia. 
Polo: Que os carregadores, os pedreiros, os lixeiros, as cozinheiras que limpam as entranhas dos frangos, as lavadeiras inclinadas sobre a pedra, as mães de família que mexem o arroz aleitando os recém-nascidos, só existem porque pensamos neles.

Kublai: Para falar a verdade, jamais penso neles.

Polo: Então não existem.

Kublai: Não me parece ser essa uma conjetura que nos convenha. Sem eles, jamais poderíamos continuar balançando encasulados em nossas redes.

Polo: Devemos rejeitar a hipótese, então. Portanto, a hipótese verdadeira é outra: são eles que existem, não nós.

Kublai: Acabamos de demonstrar que, se não existíssemos não existiríamos.

Polo: Ei-nos aqui, de fato ${ }^{4}$ (1990, p. 109-10)

Percebe-se que não só os diálogos em forma de molduras são retomados por Calvino em sua obra, mas também, uma estrutura geometricamente harmonizada, dividida em temas definidos, porém, com um resultado que permite criar fios "invisíveis" de ligação entre os temas, dando ares ao jogo combinatório e à pluralidade figurativa. Esse tipo de inspiração é encontrado também no Decameron.

Os temas escolhidos por Boccaccio revelam o olhar do escritor em conformidade com a sua época, assim, o "ideal de vida cortês" e a "dignidade do espírito" ocupam as molduras. Isso se confirma porque,

A moldura representa uma condição utópica. E é nessa condição utópica que os dez personagens da moldura narram as novelas. [...] a atitude deles nos debates das coisas narradas e mediante o comportamento deles em geral, assim descobrem o mundo ideal do Decameron dando a eles uma clara ideologia deles mesmos, isto é aos leitores daquele tempo e daqueles que virão ${ }^{5}$. (JENSEN, 1987, p. 59)

Não é diferente o olhar de Calvino sobre o homem, seus valores e suas ações diante do espaço da cidade; sobretudo, quando descobrimos que a cidade não se limita a ser o espaço ou o cenário de uma narrativa, mas que também atua, interfere e modifica as ações e os valores do homem. Desse modo, o olhar sobre a cidade ganha novas dimensões e em um processo de

\footnotetext{
${ }^{4}$ Para os trechos representativos da obra de Calvino, foi escolhida a tradução feita por Diogo Mainardi, por se tratar de uma excelente tradução e também para que todos os leitores possam usufruir da leitura com compreensão. ${ }^{5} \mathrm{La}$ cornice rappresenta una condizione utopistica. Ed è in questa condizione utopistica che i dieci personaggi della cornice si raccontano delle novelle. [...] la loro attitudine nei confronti delle cose narrate e mediante il loro comportamento in generale, discoprano il mondo ideale del Decameron rendedone chiara l'ideologia a se stessi, cioè ai lettori del loro tempo ed a quelli a venire. (JENSEN, 1987, p. 59)
} 
"reinvenção" na representação literária mobiliza movimentos da trajetória do retorno às suas raízes matriciais, recuperando, assim, o reencontro com as figuras míticas de sua origem. A mais evidente delas, nesse caso, é a figura do labirinto. Essa figura percorre toda a história da narrativa e chega até nós, numa configuração atualizada na imagem da cidade.

Chimirri (1987, p. 136) salienta que o conceito de labirinto, no texto literário, pode assumir diferente funções, podendo ser concebido como imagem do mundo físico ou psíquico ou como modo de existência. Para cada figura do mito, Chimirri concebe uma imagem pensando na criação artística: Teseu funciona como símbolo de iniciação; Ariadne, dança no rito mágico e promove uma fórmula de suplicação; caótico, desordenado e irracional (dionisíaco), o mundo toma a forma do labirinto, por outro lado, o labirinto é tomado como forma de construção racional e intelectual pensado por Dédalo na tentativa de se contrapor às forças caóticas que movimentam o mundo. Sendo assim, para o autor, o labirinto é incorporado ao texto literário de duas formas: "primeiro é o nível temático, como imagem do mundo e da psique humana, o segundo nível é o textual e eventualmente metatextual, como imagem do texto literário mesmo e dos seus aspectos de estrutura e escritura. (CHIMIRRI, 1987, p. 136)

É possível perceber essas duas funções no Le cittá invisibili, tanto o nível temático quanto o nível textual espalham o mito do labirinto. Calvino utilizou-se várias vezes desse mito e nos seus ensaios "La sfida al labirinto" (O desafio ao labirinto), "Appunti sulla narrativa come processo combinatório" (Apontamentos sobre a narrativa como processo combinatório) e "Cibernetica e fantasmi" (Cibernética e fantasmas), ele é o assunto principal.

A figura do labirinto conjuga alguns mitos que apresentam funções diferentes e que são explorados de maneira distinta nos textos literários. São os mitos de Teseu, ao lhe impor a problemática da escolha; de Ariadne, a doadora do fio "salvador"; de Dédalo, o engenhoso construtor e, do Minotauro, o monstro destruidor. Contudo, observa-se que,

Quando a literatura evoca o labirinto, o mais sensível desses desafios reside possivelmente na prova imposta a Teseu de uma escolha entre os vários caminhos para chegar até o Minotauro, e depois para sair do labirinto. Sob os passos de herói grego, abre-se de repente uma multiplicidade de caminhos, a pluralidade vertiginosa dos possíveis. A primeira tensão que o mito põe em cena é, por conseguinte, aquela do um e do múltiplo. (BRUNEL, 2000, p. 556)

Essa tensão proposta pelo mito do labirinto é, na verdade, uma problemática que impõe a questão da escolha, pois, 
Na ida e na volta, o fio ainda mágico de Ariadne indica o único caminho a percorrer. Noutras palavras, o mito levanta o problema da escolha, ao mesmo tempo que fornece o instrumento para resolvê-lo; faz entrever a pluralidade, mas, imediatamente após, oferece os meios de reduzi-la à unidade. (BRUNEL, 2000, p. 556)

A multiplicidade do mito salta da dilatação para a contração, ou seja, cria uma movimentação interna que permite a exploração do texto literário nesses dois movimentos. Desse modo, podemos identificar as escolhas de Calvino (1995, p. 212) frente à função do mito na obra literária, uma vez que, para ele, o mito é um vazio da linguagem, nela a parte da história se oculta no subterrâneo, é uma zona ainda não explorada, ainda que as palavras já tenham se esgotado. O narrar, como ato profano, das palavras quotidianas ganhas ares ritualísticos e torna o mito tácito.

A conjugação de mito e da história é articulada na figura do labirinto. Nesse procedimento temos a imagem contemporânea da cidade, porque o engenho da construção do labirinto é recuperado pela motivação de construir a cidade. O plano e o percurso desenham o labirinto mítico que encontramos dentro da metrópole moderna.

A visitação ao mito traz, para a contemporaneidade, o percurso feito pela tradição e que chega até nós na configuração das imagens do labirinto, refletidas nas imagens contemporâneas da cidade, pois

A cidade moderna sãos os ecos do labirinto - presídio complexo de ruas cruzadas e rios aparentemente sem embocadura - onde a iniciação itinerante e o fio de Ariadne se mostram tênues ou nulos. Invertendo-se uma das interpretações do mito, o labirinto aqui não é trilha para chegar-se ao centro; é, antes, marca da dispersão. Indica a vitória do material sobre o espiritual, do perecível sobre o eterno. Ou mais, o lugar descartável e o novo e sempre-igual. (GOMES, 1994, p. 64)

As categorias que marcam a imagem da cidade são as de dispersão e concentração. A marca da dispersão enreda o citadino num labirinto que se dilata em um movimento centrífugo e ultrapassa o centro metropolitano, promovendo a criação e a expansão de outros centros ao redor desse. Já a marca da concentração reúne dentro das fronteiras da cidade, o mesmo fenômeno urbano que caracteriza o labirinto, um espaço único capaz de criar inúmeras possibilidades de saída e de leitura. 
No Le città invisibili, nota-se que a utilização dessa figura ocorre de duas maneiras que conjugam as marcas de dispersão e concentração. Primeiramente tem-se o plano temático, que se dilata e transforma cada cidade em uma espécie de labirinto em miniatura. Na outra maneira, tem-se o nível de organização textual no qual, por meio da organização da obra em um número limitado de paradigmas temáticos, realiza o procedimento de alternância combinado com o da multiplicidade. (CHIMIRRI, 1987). Os primeiros paradigmas "memória”, “desejo”, "símbolos” desdobrados em cinco possibilidades constrói uma linearidade que aos poucos se dissolve em paradigmas mais abstratos, tais como os dois últimos: "contínuas" e "ocultas". Há uma construção abstracional progressiva que permite ao leitor infringir a leitura linear sem perder o sentido geral da narrativa. Esse jogo combinatório cria uma estrutura labiríntica que forma uma espécie de rede ou tecido figurativo que coloca cada cidade como um pequeno labirinto dentro do grande e definitivo labirinto da narrativa.

Assim, diante dessa "estrutura labiríntica" que preenche os níveis temático e textual, percebemos o jogo combinatório, que se abre às várias possibilidades. Para Calvino,

... a literatura é, sim, jogo combinatório que segue as possibilidades implícitas no próprio material, independentemente da personalidade do autor, mas é jogo que a um certo momento encontra-se investido de um significado inesperado, um significado não objetivo (...) de tal forma a colocar em jogo o que, em um outro plano está no coração do autor ou da sociedade à qual ele pertence. (1995, p. 214-5)

Não só o jogo combinatório soma-se à configuração do labirinto, mas também a predileção de Calvino pelas formas geométricas. Dessa forma, observamos que o uso dessas formas se estende à organização textual e auxilia na construção do labirinto.

A melhor configuração para a imagem da cidade encontra-se no labirinto. Sua modernidade, sua estrutura e topografia revisitam a tradição por meio desse mito. A soma da composição dessa obra abre-se para uma visão disfórica da imagem da cidade, pois "as cidades tomam naturalmente a forma da moderna metrópole labiríntica, onde a principal tensão emotiva reside na solitude e na falta de comunicação" (FRYE, 1977, p. 156). No texto de Calvino, no progredir dos diálogos entre Marco Polo e Kublai Khan, a focalização de cidades infernais, traduz a "tensão" que está além a oposição clássica de campo e cidade, nesse "jogo dialogal". Suas descrições retomam a figura do perder-se tal como ocorre com o labirinto, como no trecho abaixo: 
... Kublai considerava valioso em todos os fatos e notícias referidos por seu inarticulado informante era o espaço que restava em torno deles, um vazio não preenchido por palavras. As descrições das cidades visitadas por Marco Polo tinham esse dom: era possível percorrê-las com o pensamento, era possível se perder, parar para tomar ar fresco ou ir embora rapidamente. (CALVINO, 1990, p. 41)

Ao expor a maneira pela qual Marco descrevia as cidades, dando espaço para que Kublai pudesse "percorrê-las" com o pensamento, retomamos a ideia de Italo Calvino a respeito do que é um livro, para Calvino, um livro, “é um espaço no qual o leitor deve entrar, girar e quem sabe perder-se, mas em certo ponto, encontrar um saída, ou então algumas saídas.” (1993, p. VI)

Para Gomes (1994, p. 53), dramatiza-se a pólis perversa, nela a cidade descentrada, labiríntica e babélica desorganiza os sentidos e não se deixa ler. Gomes salienta que as formas foram esgotadas, diluídas e engendradas em uma armadura que desmoronou.

Renato Cordeiro Gomes, estudioso das representações da cidade na literatura, conclui sua referência ao mito da imagem da cidade através das afirmações de Borges e Benjamin:

\begin{abstract}
Assegura ainda Borges, referindo-se ao labirinto, que "um edifício construído para que alguém se perca, é símbolo inevitável da perplexidade". Caso se considere este edifício como metonímia vemos simbolizada aí a cidade moderna, criação do homem, produto da técnica, da qual ele se torna prisioneiro e na qual se perde. Daí a perplexidade desse homem que se "aventura" pelo desenho intrincado da cidade-labirinto: ele, o indeciso, o hesitante, o irresoluto, está envolvido por muitas ramificações - não sabe que caminho tomar. "O labirinto é a pátria do hesitante. O caminho daquele que teme chegar ao fim, facilmente desenhará um labirinto", já dissera Benjamin. E acrescenta: "a cidade é a realização do antigo sonho humano do labirinto". (GOMES, 1994, p. 64)
\end{abstract}

O olhar de Calvino sobre a cidade concentra-se no topos do transeunte, do viajante, de quem por ela caminha. Percorrer a cidade seja ela ficcional ou real, medieval ou contemporânea recupera o traço ancestral dos passos de Teseu. O olhar atento de Marco Polo na descrição das cidades por ele visitadas, revela a predileção pelo detalhe, pela simetria e pela combinação. Calvino (1990-B, p. 83) afirma: "Uma outra vertigem então se apodera de mim, a do detalhe, do detalhe do detalhe, vejo-me tragado pelo infinitesimal, pelo infinitamente mínimo, como antes me dispersava no infinitamente vasto.” Esses detalhes projetam-se nas descrições das 
cidades ou dos habitantes que Polo encontra em suas viagens. Foram selecionados três trechos que procurarão evidenciar esse olhar, o olhar do viajante, carregado de detalhes:

1) Passa uma moça balançando uma sombrinha apoiada no ombro, e um pouco das ancas, também. Passa uma mulher vestida de preto que demonstra toda a sua idade, com os olhos inquietos debaixo do véu e os lábios tremulantes. Passa um gigante tatuado; um homem jovem com os cabelos brancos; uma anã; duas gêmeas vestidas de coral. (1990, p. 51)

2) Por longo tempo, Pirra foi para mim uma cidade encastelada nas encostas de um golfo, com amplas janelas e torres, fechada como uma taça, com uma praça em seu centro profundo como um poço e com um poço sem seu centro. (1990, p. 87)

3) No lugar dos textos, imagina-se que a cidade ínfera possui latas de lixo invertidas, das quais transbordam cascas de queijo, embalagens gordurosas, água de louça suja, restos de espaguete, velhas vendas. (1990, p. 103)

A seleção de imagens e figuras que ocupam as cidades descritas sugere a precisão do detalhe e a atenção dos olhos do viajante, do transeunte, daquele que passeia. $\mathrm{O}$ andar de Marco Polo restaura o caminhar de Teseu, ambos voltados para seus objetivos maiores, o primeiro, de agradar ao imperador Tártaro e o segundo, matar o Minotauro. Os fios das caminhada recuperam a figura mítica de Ariadne, na tentativa de doar o fio salvador que indica a saída ou como na contemporaneidade, muitas saídas; além de retomar a figura de Dédalo como o grande engenheiro construtor, tal qual o escritor, engenhoso das letras que faz com que o leitor, primeiro se perca e depois se encontre.

Sendo assim, considera-se, portanto, que o percurso através do labirinto na obra Le cittá invisibili estende-se ao conceito de literatura e metaforiza o desejo de dar ao texto literário a multiplicidade de saídas, de interpretações, de leituras possíveis e imagináveis, buscados por Calvino na composição da obra. O diálogo com o texto da tradição, Decameron de Boccaccio, revigora o movimento centrípeto que a Literatura executa de forma consciente e intencional. Além disso, vislumbra-se que as isotopias da perda e da confusão, presentes no labirinto, constituem os fios de significação que se entrelaçam na figura da cidade tanto medieval quanto moderna, dando-lhe o caráter disjuntivo e disfórico inerente à matriz de que decorrem.

\section{Referências}

BAKHTIN, M. Problemas da poética de Dostoiévski. (Tradução de Paulo Bezerra). 2 ed. Rio de Janeiro, Forense Universitária, 1997. 
BRUNEL, P. Dicionário de mitos literários. Tradução de Carlos Sussekind, Jorge Laclette, Maria Thereza Rezende Costa, Vera Whately. Rio de Janeiro: José Olympio, 2000.

CAlvino, I. As cidades invisíveis. 4 ed. (Tradução de Diogo Mainardi). São Paulo: Companhia das Letras, 1990.

. Seis propostas para o próximo milênio: lições americanas. 2 ed. (Tradução de Ivo Barroso). São Paulo: Companhia das Letras, 1990-B.

Le città invisibili. 1 ed. Milano: Arnoldo Mondadori, 1993.

. Una pietra sopra. 1 ed. Milano: Arnoldo Mondadori, 1995.

CHIMIRRI, G. V. Italo Calvino: tra realtà e la favola. Catania: Cooperativa Universitaria Editrice Catanese di Magistero Via Etnea, 1987.

FRYE, N. Anatomia da crítica. (Tradução de Péricles Eugênio da Silva Ramos). São Paulo: Cultrix, 1977.

GOMES, R. C. Todas as cidades, a cidade: literatura e experiência urbana. Rio de Janeiro: Rocco, 1994.

IOZZI, A. A poética da reescritura: uma leitura pós-moderna de Le città invisibili de Italo Calvino. São Paulo, 1998. Dissertação (Mestrado em Letras - Área de Teoria da Literatura e Literatura Comparada) - Universidade de São Paulo.

. A cidade como linguagem: a poética topográfica de Le città invisibili. In: $\mathbf{O}$ italiano falado e escrito. São Paulo: Humanitas/FFLCH/USP, 1998.

A experiência literária e a contribuição ensaística de Italo Calvino. In: Insieme, número 8. 2001.

JENSEN, K. Aspetti cortesi ed utopistici nei personaggi della cornice del Decameron di Giovanni Boccaccio. In: Revue Romane, numero 22, 1987.

PAZZAGLIA, M. Dal Medioevo all'umanesimo: Antologia con pagine critiche e un profilo di storia letteraria. 3 ed. Zanichelli, 1993.

PRECIOSO, A. L. Invisibilidade e invenção: a poética das cidades em Italo Calvino e Ferreira Gullar. Dissertação (Mestrado em Letras - Área Teoria da Literatura e Literatura Comparada) - Universidade Estadual Paulista - Campus de São José do Rio Preto, 2003. 
A. L. Precioso

Um passeio pela estrutura labiríntica de Le città invisibili de Ítalo Calvino

Artigo recebido em: 19.11.2019

Artigo aceito para publicar em: 26.11.2019 